\title{
VACCINATION AGAINST COVID-19: CONTRIBUTION TO THERAPY AND PROGNOSIS
}

\author{
Kartashova MK $\bowtie$, Kiseleva YaV, Semenistaya MCh, Pavlov ChS
}

Sechenov First Moscow State Medical University, Moscow, Russia

The article elaborates on the principles and modern methodology of evaluating vaccine safety, efficacy and effectiveness. The main parameters and criteria of successful immunization are described in plain and concise language. Special attention is paid to the analysis of clinical and epidemiological aspects of vaccination against Covid-19. The article provides the most recent epidemiological statistics on this disease. A report of the efficacy and safety of the BNT162b2 vaccine is given as an example.

Keywords: vaccine efficacy, vaccine safety, COVID-19, immunization

$\square$ Correspondence should be addressed: Kartashova Maria

Trubetskaya, 8, b. 2, Moscow, 119048, Russia; kmk8963@gmail.com

Received: 08.04.2021 Accepted: 15.05.2021 Published online: 30.06.2021

DOI: $10.24075 /$ medet.2021.017

\section{ВАКЦИНОПРОФИЛАКТИКА СОVID-19: ОЦЕНКА ВКЛАДА В СХЕМАХ ТЕРАПИИ И ПРОГНОЗА ИНФЕКЦИИ}

\author{
М. К. Карташова , Я. В. Киселева, М. Ч. Семенистая, Ч. С. Павлов
}

Первый Московский государственный медицинский университет им. И. М. Сеченова, Москва, Россия

\begin{abstract}
В статье подробно освещены принципы и современная методология оценки эффективности и безопасности применения вакцин. В доступной форме, коротко и лаконично характеризованы основные показатели и критерии оценки вакцинопрофилактики. Особое внимание удалено анализу клинических и эпидемиологических особенностей вакцинопрофилактики COVID-19. В тексте приводятся последние статистические данные заболеваемости инфекцией COVID-19. В качестве примера представлена оценка эффективности конкретного препарата (BNT162b2), который применяется, с целью вакцинопрофилактики инфекции COVID-19.
\end{abstract}

Ключевые слова: эффективность вакцины, безопасность вакцины, COVID-19, вакцинопросилактика.

$\bowtie$ Для корреспонденции: Карташова Мария Константиновна

Трубецкая ул., д. 8 стр. 2, г. Москва, 119048, Россия; kmk8963@gmail.com

Поступила: 08.04.2021 Статья принята к печати: 15.05.2021 Опубликована онлайн: 30.06.2021

DOI: $10.24075 /$ medet.2021.017

\section{INTRODUCTION}

The first reports of the novel coronavirus disease, which is known as Covid-19 and is caused by SARS-CoV-2, came from Wuhan, China, in December 2019. In only a matter of months, the infection spread to other continents and sparked a pandemic. By June 2021, there were over 183 million reported cases of Covid-19 worldwide, with the total death toll of 3.9 million [1].

The course of Covid-19 varies from asymptomatic infection to severe pneumonia and death. Risk factors predisposing to severe SARS-CoV-2 infection remain understudied [2]. Today, one of the top public health priorities is vaccination against the disease because there has been no steady decline in Covid-19 morbidity and mortality in the past year [1]. To this day, there are no consensus approaches to the pathogenetic therapy of the infection [3]. Since the beginning of the pandemic, Covid-19 treatment guidelines have been revised a few times to take into account the accumulated data about the pathogenesis of the disease and its course in different subpopulations. At the outset of the pandemic, treatment regimens for Covid-19 included drugs that had been previously approved to fight other infection: chloroquine, hydroxychloroquine, remdesivir, favipiravir and some others $[4,5]$. Today, the focus has shifted to anti-inflammatory drugs, anticoagulants, convalescent plasma, and symptomatic therapy [6]. With Covid-19, the outcome and survival are difficult to predict, and the disease has long-term sequelae, including post-Covid syndrome manifested as neurological symptoms, pulmonary fibrosis, renal failure, myocarditis, gastrointestinal disorders, etc. [7-9]. Given that the pathogenesis of the disease is not fully understood and treatment options are limited, vaccination remains the only solution that could prevent the infection and its complications [6].

The discovery of vaccines is a crucial milestone in the history of medical science. Vaccination has significantly increased life expectancy and had a positive effect on human health. The history of contemporary vaccines began in the late $18^{\text {th }}$ century when Edward Jenner invented a vaccine against small pox. Since then, there has been a tremendous progress in vaccinology; due to successful vaccination programs, many dangerous infections are now under control, including small pox, polio, rabbis, tetanus, pertussis, measles, mumps and rubella. Technological advancements in vaccine manufacturing have facilitated their mass production, leading to a significant reduction in morbidity and mortality from infectious diseases in the $21^{\text {st }}$ century. As more knowledge is accrued about microbiology and immunology, indications for immunization against infections continue to expand [11].

According to $\mathrm{WHO}$, the $\mathrm{BCG}$ vaccine against tuberculosis prevents TB-associated deaths in $65 \%$ of cases, deaths from tuberculous meningitis in $64 \%$ of cases and deaths from disseminated TB in 78\% of cases. A report from the 1920s reveals that BCG vaccination of Norwegian nursing students led to an over $80 \%$ reduction in pulmonary TB incidence in this subpopulation during a 3 -year-long follow-up period [12]. 
WHO reports that by July 2021, there were 13 registered vaccines against Covid-19. Three of them were designed in Russia [13].The most discussed aspects of vaccination are the efficacy and safety of vaccines in different groups of patients, including severely ill individuals or those with pre-existing conditions, who are at greater risk for severe Covid-19 and death [7].

\section{IMPORTANCE OF IMMUNIZATION AGAINST COVID-19}

Today the efficacy and safety of vaccines against Covid-19 are high on the public health agenda [14]. Before a vaccine is approved for use, its efficacy and safety need to be proved in a clinical trial. Knowledge of basic vaccine efficacy criteria plays the crucial role in decision making about mass immunization in the general population and medical communities. One of the key steps toward promoting vaccination and building confidence in vaccines is dissemination of knowledge about vaccine epidemiology among clinicians, public health experts, politicians, and the general population [15]. Raising awareness about the basic principles of vaccine testing may help to bridge the gap between public health fundamental sciences and clinical practice [16].

The aim of this article was to analyze the main criteria of vaccine efficacy. The article also discusses the role of immunization in therapeutic regimens for Covid-19 and the outcomes of the disease.

\section{MEASURING VACCINE EFFICACY}

Studies investigating the efficacy and safety of vaccines against Covid-19 are intended to answer the question which of the many vaccines, whose number is continuously growing, is the right one. Below we describe the main terms used in qualitative vaccine analysis.

In the formulas below "a" and "b" represent the number of vaccinated individuals who have or have not contracted the infection (which is Covid-19 in our case), respectively; "c" and "d" represent the number of unvaccinated individuals who have or have not contracted the infection, respectively.

Absolute risk reduction (ARR) is the absolute difference in the risk of infection between the vaccinated and unvaccinated groups; it is calculated by the formula:

$$
A R R=\left[\frac{c}{(c+d)}-\frac{a}{(a+b)}\right]=\left[n_{u n v}-n_{v}\right],
$$

where $n_{u n v}=\frac{c}{(c+d)}$ and $n_{v}=\frac{a}{(a+b)}$ are the incidence rates of the infection in the unvaccinated and vaccinated groups, respectively.

The mathematic difference in the rate of infection between the groups $n_{u n v}-n_{v}$ is also known as vaccine preventable disease incidence (VPDI).

Number needed to treat (NNT) is the number of individuals that need to be vaccinated in order to prevent one case of infection:

$$
N T T=\frac{1}{A R R}
$$

Relative risk (RR) compares the probability of infection between the vaccinated and unvaccinated groups:

$$
R R=\frac{n_{v}}{n_{u n v}}=\frac{(a /(a / b)))}{(c /(c-d)))}
$$

Odds ratio (OR) is the ratio of the probability of contracting the infection for a vaccinated individual to the probability of contracting the infection for an unvaccinated individual:

$$
O R=\frac{(a / c)}{(b / d)}=\frac{a d}{b c} \rightarrow
$$

\section{VACCINE EFFICACY}

Vaccine efficacy is tested in randomized placebo-controlled clinical trials $(\mathrm{RCT})$. It is essentially a percent reduction in the rate of infection in the vaccinated group vs. the control group. This parameter is tested during phase II and III trials.

Relative risk reduction (RRR), or vaccine efficacy (VE):

$$
R R R=V E=1-R R=1-\frac{n_{v}}{n_{u n v}}
$$

Vaccine efficacy is also known as a rate fraction, etiologic fraction and attributable fraction. It describes the proportion of infection incidents prevented by the vaccine. Unlike VE, VPDI is not a proportion but a frequency. Mathematically, VPDI equals $\mathrm{n}_{\text {unv }} \times V E$. This definition shows that VPDI takes into account both VE and the background rate of infection. Vaccine efficacy may not always reflect the full epidemiological picture and can be relatively low, with the burden of the disease remaining high. VPDI may a more appropriate measure of the epidemiological situation and can play a considerable role in vaccine approval and development of guidelines for vaccine use.

\section{Vaccine effectiveness (VEF)}

Vaccine effectiveness is measured as a percent reduction in the number of infections in the vaccinated vs. unvaccinated groups of the unselected population in real-world conditions during the actual immunization campaign [17].

$$
V E F=1-\frac{n_{n}}{n_{u n v}},
$$

where $n_{n}$ is the rate of random infections in the population. This parameter relates to VE as shown in the formula:

$$
V E F=V E \times P P V,
$$

where PPV is the vaccinated proportion of the population, also known as coverage.

Basic reproductive number $(\mathrm{R} 0)$ is the average number of secondary cases generated by a single primary case in a susceptible population. This parameter can be measured by means of serological tests.

In order for an epidemic to unfold in a susceptible population, $R 0$ needs to be $>1$. By contrast, if $R 0$ is $<1$, the epidemic subsides because the pool of infected individuals shrinks.

Effective reproductive rate $(\mathrm{Re})$ is the average number of secondary cases per one primary case in a population consisting of both susceptible and unsusceptible individuals.

$$
R e=R O \times x,
$$

where $x$ is the susceptible proportion of the population.

Herd immunity threshold (HIT): herd immunity occurs when a substantial proportion of the population has been vaccinated, ensuring that susceptible individuals are protected against the infection. HIT is the proportion of the population that needs to have immunity against the infection in order to contain its spread. If HIT is achieved through, say, immunization, then every administered vaccine dose reduces the risk of new transmission (i.e., $R e=1$ ) and the infection becomes stable in this population [16]. 
Below, we provide an example of a clinical trial conducted by Polack et al. [17] evaluating the efficacy and safety of the BNT162b2 vaccine against Covid-19. A double-blind placebocontrolled trial was conducted among individuals aged 16 years and above from 152 centers around the world (USA: 130 centers, Argentina: 1; Brazil: 2; South Africa: 4; Germany: 6; Turkey: 9). The allocation ratio was 1:1. A total of 43,548 participants underwent randomization; of them 21, 720 received 2 doses of BNT162b2 (30 $\mu$ g per dose) with a 21-day interval and 21,728 received 2 doses of a placebo.

The safety of the vaccine was analyzed on a sample of 37,706 participants. The follow-up period was at least 2 months after the administration of the second dose. Of 37,706 participants 49\% were women, 83\% were Caucasian, 9\% were Black or African Americans, 28\% were Hispanic, 35\% were obese (BMI $\geq 30.0$ ), and $21 \%$ had at least one preexisting condition. The mean age was 52 years; $42 \%$ of the participants were older than 55 years [18].

The following parameters were evaluated: pain at the injection site and asthenic syndrome. Among severe adverse events were shoulder injury caused by the injection, axillary lymphadenopathy, paroxysmal ventricular arrhythmia, and limb paresthesia. There were 2 deaths in the vaccinated group (one from acute coronary syndrome, the other one from cardiac arrest). Four participants died in the placebo group (two from unknown causes, one from hemorrhagic stroke, and one from myocardial infarction). The frequency of adverse events was low and did not differ between the groups [18].

The efficacy of the BNT162b2 vaccine was computed as $(100 \times(1-I R R)$, where IRR is the calculated ratio of confirmed Covid-19 cases per 1,000 person-years of follow-up in the vaccinated group to the rate of infection in the placebo group.
BNT162b2 was found to be $95 \%$ effective in preventing Covid-19 (95\% Cl: 90.3-98.6). The 95.0\% Cl for vaccine efficacy and the probability of vaccine efficacy of over $30 \%$ were calculated using a Bayesian beta-binomial model. In the final analysis, the success threshold for the probability of vaccine efficacy over $30 \%$ was set to $98.6 \%$ to compensate for the interim analysis and control the overall type 1 error rate at $2.5 \%$. Primary and secondary efficacy end points were evaluated sequentially in order to control type 1 family-wise error rate at $2.5 \%$. In the vaccinated group, there were 8 cases of infection 7 days after the administration of the second dose. There were 162 cases of Covid-19 in the placebo group. Vaccine efficacy was very similar (90 to 100\%) in all the subgroups by age, sex, race, ethnicity, BMI, and preexisting conditions [18].

\section{CONCLUSION}

The use of adequate methods for vaccine evaluation and timely dissemination of data generated by the clinical trials of antiCovid-19 vaccines are a crucial contributor to the successful fight against this infection, helping to promote the idea of vaccination in the population. The methods for evaluating vaccine efficacy, effectiveness and safety described in this article might improve immunization coverage, especially in susceptible populations at risk for severe Covid -19 and death from this infection. These goals can be achieved through the use of modern technologies for vaccine manufacturing and by providing accurate statistics on Covid-19 epidemiology, vaccine efficacy, safety and immunogenicity. In the absence of a consensus view on immunization, society needs more information about methods for vaccine evaluation and their role in preventing the risks associated with Covid-19 [19].

\section{References}

1. ArcGIS. COVID-19 Dashboard by the Center for Systems Science and Engineeing (CSSE) at Johns Hopkins University (JHU).; 2021. [The dashboard and information regarding the COVID-19 situation in the world]. Available at: https://www.arcgis.com/apps/ dashboards/bda7594740fd40299423467b48e9ecf6 Accessed: 25.07.2021.

2. Adil MT, Rahman R, Whitelaw D, et al. SARS-CoV-2 and the pandemic of COVID-19. Postgrad Med J. 2021;97(1144):110116. DOI:10.1136/postgradmedj-2020-138386

3. Ita K. Coronavirus Disease (COVID-19): Current Status and Prospects for Drug and Vaccine Development. Arch Med Res. 2021;52(1):15-24. DOl:10.1016/j.arcmed.2020.09.010

4. Liu X, Liu C, Liu G, Luo W, Xia N. COVID-19: Progress in diagnostics, therapy and vaccination. Theranostics. 2020;10(17):7821-7835. DOI:10.7150/thno.47987

5. Triggle CR, Bansal D, Farag EABA, Ding $H$, Sultan AA. COVID-19: Learning from Lessons To Guide Treatment and Prevention Interventions. Rosenberg HF, ed. mSphere. 2020;5(3). DOI:10.1128/mSphere.00317-20

6. Gavriatopoulou M, Ntanasis-Stathopoulos I, Korompoki E, et al. Emerging treatment strategies for COVID-19 infection. Clin Exp Med. 2021;21(2):167-179. DOI:10.1007/s10238-020-00671-y

7. Wang F, Kream RM, Stefano GB. Long-Term Respiratory and Neurological Sequelae of COVID-19. Med Sci Monit. 2020;26. DOI:10.12659/MSM.928996

8. Chung JY, Thone MN, Kwon YJ. COVID-19 vaccines: The status and perspectives in delivery points of view. Adv Drug Deliv Rev. 2021;170:1-25. DOI:10.1016/j.addr.2020.12.011

9. Alhazzani W, Møller MH, Arabi YM, et al. Surviving Sepsis Campaign: guidelines on the management of critically ill adults with Coronavirus Disease 2019 (COVID-19). Intensive Care Med. 2020;46(5):854-887. DOI:10.1007/s00134-020-06022-5
10. Zhao J, Zhao S, Ou J, et al. COVID-19: Coronavirus Vaccine Development Updates. Front Immunol. 2020;11:602256. DOI:10.3389/fimmu.2020.602256

11. Plotkin S. History of vaccination. Proc Natl Acad Sci. 2014;111(34):12283-12287. DOI:10.1073/pnas.1400472111

12. World Health Organisation. BCG Vaccine. Data from WHO.; 2008. [The WHO statistical data in the field of BCG Vaccines]. Available at: https://www.who.int/immunization/BCG_8May2008_RU.pdf Accessed - 20.07.2021. (In Russ.)

13. World Health Organisation. Coronavirus disease (COVID-19): Vaccines. Published June 22, 2021. [Online resource]. Available at: https://www.who.int/news-room/q-a-detail/coronavirusdisease-(covid-19)-vaccines?adgroupsurvey $=\{$ adgroupsurvey $\}$ \& gclid=CjOKCQjwOK-HBhDDARIsAFJ6UGiXf1LSjnMFSnaCNgstv aWHeYguB50LJeEBSaNHqpXR1i64lwqO6AsaAodHEALw_wcB Accessed - 10.07.2021.

14. Ye T, Zhong Z, García-Sastre A, Schotsaert M, De Geest BG. Current Status of COVID-19 (Pre)Clinical Vaccine Development. Angew Chem Int Ed. 2020;59(43):18885-18897. DOl:10.1002/anie.202008319

15. Frederiksen LSF, Zhang Y, Foged C, Thakur A. The Long Road Toward COVID-19 Herd Immunity: Vaccine Platform Technologies and Mass Immunization Strategies. Front Immunol. 2020;11:1817. DOl:10.3389/fimmu.2020.01817

16. Dasgupta S. A Review of Vaccine Efficacy Measures. 1(1):4.

17. Crowcroft NS, Klein NP. A framework for research on vaccine effectiveness. Vaccine. 2018;36(48):7286-7293. DOI:10.1016/j. vaccine.2018.04.016

18. Polack FP, Thomas SJ, Kitchin N, et al. Safety and Efficacy of the BNT162b2 mRNA Covid-19 Vaccine. N Engl J Med. 2020;383(27):2603-2615. DOI:10.1056/NEJMoa2034577

19. Stern PL. Key steps in vaccine development. Ann Allergy Asthma Immunol. 2020;125(1):17-27. DOI:10.1016/.anai.2020.01.025 


\section{Литература}

1. ArcGIS. COVID-19 Dashboard by the Center for Systems Science and Engineeing (CSSE) at Johns Hopkins University (JHU).; 2021. [Электронныый ресурс]. Режим доступа: https://www.arcgis. com/apps/dashboards/bda7594740fd40299423467b48e9ecf6 (дата обращения: 25.07.2021).

2. Adil MT, Rahman $R$, Whitelaw $D$, et al. SARS-CoV-2 and the pandemic of COVID-19. Postgrad Med J. 2021;97(1144):110116. DOI: 10.1136/postgradmedj-2020-138386

3. Ita K. Coronavirus Disease (COVID-19): Current Status and Prospects for Drug and Vaccine Development. Arch Med Res. 2021;52(1):15-24. DOI:10.1016/j.arcmed.2020.09.010

4. Liu X, Liu C, Liu G, Luo W, Xia N. COVID-19: Progress in diagnostics, therapy and vaccination. Theranostics. 2020;10(17):7821-7835. DOI:10.7150/thno.47987

5. Triggle CR, Bansal D, Farag EABA, Ding $H$, Sultan AA COVID-19: Learning from Lessons To Guide Treatment and Prevention Interventions. Rosenberg HF, ed. mSphere. 2020;5(3). DOI:10.1128/mSphere.00317-20

6. Gavriatopoulou M, Ntanasis-Stathopoulos I, Korompoki E, et al. Emerging treatment strategies for COVID-19 infection. Clin Exp Med. 2021;21(2):167-179. DOI:10.1007/s10238-020-00671-y

7. Wang F, Kream RM, Stefano GB. Long-Term Respiratory and Neurological Sequelae of COVID-19. Med Sci Monit. 2020;26. DOI:10.12659/MSM.928996

8. Chung JY, Thone MN, Kwon YJ. COVID-19 vaccines: The status and perspectives in delivery points of view. Adv Drug Deliv Rev. 2021;170:1-25. DOI:10.1016/j.addr.2020.12.011

9. Alhazzani W, Møller MH, Arabi YM, et al. Surviving Sepsis Campaign: guidelines on the management of critically ill adults with Coronavirus Disease 2019 (COVID-19). Intensive Care Med. 2020;46(5):854-887. DOI:10.1007/s00134-020-06022-5
10. Zhao J, Zhao S, Ou J, et al. COVID-19: Coronavirus Vaccine Development Updates. Front Immunol. 2020;11:602256. DOI:10.3389/fimmu.2020.602256

11. Plotkin S. History of vaccination. Proc Natl Acad Sci. 2014;111(34):12283-12287. DOI:10.1073/pnas.1400472111

12. WHO. BCG Vaccine. Data from WHO.; 2008. ГЭлектронныый ресурс]. Режим доступа: https://www.who.int/immunization/ BCG 8May2008_RU.pdf (дата обращения - 20.07.2021).

13. World Health Organisation. Coronavirus disease (COVID-19): Vaccines. Published June 22, 2021. [Электронныый ресурс]. Режим доступа: https://www.who.int/news-room/q-a-detail/ coronavirus-disease-(covid-19)-vaccines?adgroupsurvey=\{adgroup survey\}\&gclid=CjOKCQjwOK-HBhDDARIsAFJ6UGiXf1LSjnMFSnaC NgstvaWHeYguB50LJeEBSaNHqpXR1i64IwqO6AsaAodHEALw_ wcB (дата обращения - 10.07.2021).

14. Ye T, Zhong Z, García-Sastre A, Schotsaert M, De Geest BG. Current Status of COVID-19 (Pre)Clinical Vaccine Development. Angew Chem Int Ed. 2020;59(43):18885-18897. DOI:10.1002/anie.202008319

15. Frederiksen LSF, Zhang Y, Foged C, Thakur A. The Long Road Toward COVID-19 Herd Immunity: Vaccine Platform Technologies and Mass Immunization Strategies. Front Immunol. 2020;11:1817. DOI:10.3389/fimmu.2020.01817

16. Dasgupta S. A Review of Vaccine Efficacy Measures. 1(1):4.

17. Crowcroft NS, Klein NP. A framework for research on vaccine effectiveness. Vaccine. 2018;36(48):7286-7293. DOI:10.1016/j. vaccine.2018.04.016

18. Polack FP, Thomas SJ, Kitchin N, et al. Safety and Efficacy of the BNT162b2 mRNA Covid-19 Vaccine. N Engl J Med. 2020;383(27):2603-2615. DOI:10.1056/NEJMoa2034577

19. Stern PL. Key steps in vaccine development. Ann Allergy Asthma Immunol. 2020;125(1):17-27. DOI:10.1016/j.anai.2020.01.025 